\title{
SISTEM PENYEWAAN ALAT-ALAT SELAM BERBASIS WEBSITE PADA FISHERIES DIVING CLUB UNIVERSITAS HASANUDDIN
}

\author{
Fajar Ramadhan ${ }^{1}$, Suranto Saputra ${ }^{2}$, Aswin Fitriansyah ${ }^{3}$ \\ Program Studi Teknik Informatika, Universitas Indraprasta PGRI \\ Jalan Raya Tengah No. 80, Kelurahan Gedong, Pasar Rebo, Jakarta Timur \\ Email: fajar.ramadhans@gmail.com ${ }^{1}$, surantounindra@yahoo.co.id ${ }^{2}$, aswinf.und@gmail.com ${ }^{3}$
}

\begin{abstract}
Abstrak
Tujuan Penelitian adalah untuk membuat sistem penyewaan alat-alat selam dan snorkeling berbasis web yang efisien dan dapat membantu kinerja admin pada saat transaksi penyewaan alat-alat selam dan snorkeling. Metode yang digunakan oleh peneliti dalam penelitian ini adalah metode penelitian deskriptif kualitif yaitu suatu bentuk penelitian yang bertujuan untuk memberikan gambaran sistematik dan akurat mengenai fakta, sifat, dan hubungan antara fenomena yang diteliti dan berusahan untuk menekankan pada pemecah masalah aktual dengan cara mengumpulkan, menyajikan, atau menginterprestasikan serta menganalisis data dan informasi yang relevan untuk memberikan gambaran yang cukup jelas atas objek penelitian. Peneliti menarik kesimpulan bahwa aplikasi yang telah dibuat untuk memudahkan dan membantu dalam proses pengolahan dan penginputan data agar lebih efektif dan efisien.
\end{abstract}

Kata Kunci: Sistem Penyewaan Alat-alat Selam dan Snorkeling, Website.

\begin{abstract}
The aim of the research is to create an efficient web-based diving and snorkeling equipment rental system that can help admin performance during scuba and snorkeling equipment rental transactions. The method used by researchers in this research is a method of descriptive qualifications, a form of research aimed at providing a systematic and accurate picture of the facts, properties, and relationships between the phenomena Researched and engaged to emphasize the actual troubleshooter by collecting, presenting, or interpreting and analyzing the relevant data and information to provide a reasonably clear picture of the research object. Researchers draw conclusions that applications have been made to facilitate and assist in the processing and input of data to be more effective and efficient.
\end{abstract}

Keyword: Systems Rental of Diving and Snorkeling Equipment, Website.

\section{PENDAHULUAN}

Teknologi informasi pada era saat ini telah banyak membuat perubahan pada cara kerja dan berpikir manusia. Tanpa teknologi informasi, suatu perusahaan atau instansi tidak dapat menjalankan kegiatan operasional dalam ruang lingkup kerja secara optimal. Oleh karena itu, untuk menunjang kegiatan operasional dalam penyelesaian tugas, diperlukan suatu sistem informasi yang baik untuk mendapatkan data yang diperlukan dengan cepat dan akurat. Menurut (Subhan, 2012), sistem dapat diartikan sebagai suatu kumpulan atau himpunan dari unsur, komponen atau variabelvariabel yang terorganisasi, saling berinteraksi saling bergantungan satu sama lain dan terpadu. Menurut (Sutabri, 2012), sistem adalah sekelompok unsur yang erat hubungannya satu dengan yang lain, yang berfungsi bersama-sama untuk mencapai tujuan tertentu. Banyak instansi perusahaan besar memanfaatkan teknologi informasi sebagai alat bantu dalam menyelesaikan permasalahan yang sering dihadapi. Masalah ini dapat berupa informasi dari data - data lapangan yang ada yang kemudian diolah sesuai dengan kebutuhan.

Fisheries Diving Club (FDC) Universitas Hasanuddin adalah organisasi mahasiswa dalam lingkungan Jurusan Perikanan Universitas Hasanuddin yang bersifat semiotonom dan langsung berada di bawah induk organisasi POSSI (Persatuan Olahraga Selam Seluruh Indonesia). Organisasi ini bertempat di Jurusan Perikanan dan Marine Station FIKP Universitas Hasanuddin di Pulau Barrang Lompo Makassar. FDC Universitas Hasanuddin dibentuk dengan maksud untuk menyalurkan minat dan bakat mahasiswa Perikanan Universitas Hasanuddin dalam kegiatan selam. Pengembangan sistem informasi penyewaan merupakan hasil perkembangan teknologi sebuah aplikasi komputer yang nantinya diharapkan dapat membantu dan memudahkan pekerjaan 
manusia. Diharapkan pula sistem ini dapat membantu dalam kegitan sehari hari agar dapat efektif dan efisiensi, penelitian ini berfokus pada penyewaan alat-alat selam dan snorkeling pada Fisheries Diving Club (FDC) Universitas Hasanuddin.

Berdasarkan uraian pada latar belakang masalah dan identifikasi masalah diatas, maka dapat dilihat permasalahan yang akan dikaji dalam penelitian ini dan dapat dirumuskan masalahnya sebagai berikut yaitu bagaimana sistem penyewaan alat-alat selam dan snorkeling yang sedang berjalan saat ini pada Fisheries Diving Club (FDC) Universitas Hasanuddin? Bagaimana perancangan sistem penyewaan alat-alat selam dan snorkeling pada Fisheries Diving Club (FDC) Universitas Hasanuddin sehingga dapat mempermudah transaksi penyewaan alat-alat selam snorkeling dan mempermudah pencarian data dan mempercepat pembuatan laporan? Bagaimana implementasi dari rancangan sistem penyewaan alat-alat selam dan snorkeling pada Fisheries Diving Club (FDC) Universitas Hasanuddin?

Menurut (Safaat, 2012), perangkat lunak aplikasi adalah suatu subkelas perangkat lunak komputer yang memanfaatkan kemampuan komputer langsung untuk melakukan suatu tugas yang diinginkan pengguna. Menurut (Kimmel, 2011) dikemukakan bahwa penyewaan adalah Perjanjian dimana pemilik dari aset perusahaan memungkinkan pihak lain untuk menggunakan aset yang ada untuk jangka waktu tertentu pada harga yang telah disepakati. Menurut (Parno, 2009), Diagram alir data (DAD) adalah alat pembuatan model yang memungkinkan profesional sistem untuk menggambarkan sistem sebagai suatu jaringan proses fungsional yang dihubungkan satu sama lain dengan alur data, baik secara manual maupun komputerisasi. Menurut (Sukamto, 2014), Entity Relationship Diagram (ERD) adalah pemodelan awal basis data yang akan dikembangkan berdasarkan teori himpunan dalam bidang matematika untuk pemodelan basis data relasional. Menurut (Rahardja, 2011), database adalah kumpulan fakta-fakta sebagai respresentasi dari dunia nyata yang saling berhubungan dan mempunyai arti tertentu. HTML (HyperText Markup Language) merupakan salah satu format yang digunakan dalam pembuatan dokumen dan aplikasi yang berjalan dihalaman web. (Ardhana, 2012), PHP merupakan bahasa pemograman berbasis server - side yang dapat melakukan parsing script php menjadi script web sehingga dari sisi client menghasilkan suatu tampilan yang menarik. Menurut (Raharjo, 2011), MySQL merupakan RDBMS atau server database yang mengelola database dengan cepat menampung dalam jumlah sangat besar dan dapat di akses oleh banyak user. Menurut (Nugroho, 2013), XAMPP adalah pake program web lengkap yang dapat anda pakai untuk belajar pemrograman web, khususnya PHP dan $M y S Q L$. Oleh sebab itu dalam merancang sistem diperlukan analisis dari komponen-komponen penting yang mempengaruhi sistem tersebut.

\section{PENELITIAN RELEVAN}

Mochammad Gibran Akbar melakukan penelitian yang berjudul Aplikasi Penyewaan Kamera Berbasis Web Pada Start Up Sewa Kameraku. Tujuan dari penelitian ini adalah untuk mengetahui pengolahan data pemesanan rental kamera yang sedang berjalan di CV Sewa Kameraku, merancang dan membuat aplikasi penyewaan kamera berbasis web di CV Sewa Kameraku, membangun sistem sewa kamera pada CV Sewa kameraku agar dapat mengolah data kamera dan aksesoris lainnya sehingga mempermudah proses pendataan, mempermudah CV Sewa Kameraku dalam mengelola pelanggan yang ingin menyewa kamera.

Deni Hermawan melakukan penelitian yang berjudul Sistem Informasi Penyewaan Alat Kemping Berbasis Web Pada CV. Green Camp Bandung. Tujuan dari penelitian ini adalah untuk mengetahui sistem penyewaan peralatan kemping pada CV. Green Camp Bandung, untuk membangun program aplikasi yang di butuhkan Green Camp Bandung berbasis web untuk membantu dalam proses penyewaan peralatan kemping seperti proses pengolahan penyewaan seperti pengiriman, pengembalian peralatan dan pembuatan laporan transaksi, untuk mengimplementasikan rancangan yang telah di buat ke coding agar sistem dapat berjalan dan membentuk suatu program aplikasi, untuk melakukan testing pada sistem yang telah di bangun bertujuan untuk mencari bug atau eror pada aplikasi jika terjdi demikian maka aplikasi akan di perbaiki dari kesalahan tersebut.

Hadi Zakaria melakukan penelitian yang berjudul Perancangan Aplikasi Penjualan dan Penyewaan Mobil Berbasis Web Dengan Menggunakan Model Waterfall Pada CV. Dhiyara Anugrah. Tujuan dari penelitian ini adalah untuk aplikasi yang dibangun dapat mempermudah pihak-pihak yang berkepentingan untuk mendapatkan informasi yang semestinya dengan lebih mudah, fleksibel dan 
akurat, berdasarkan hasil perancangan aplikasi penjualan dan penyewaan mobil pada CV. Dhiyara Anugrah tersebut dapat memudahkan customer untuk mengetahui harga jual dan sewa mobil tanpa harus datang ke CV. Dhiyara Anugrah, aplikasi ini dapat diakses melalui web browser dan juga terbuka untuk semua orang yang ingin mengetahui informasi tentang CV. Dhiyara Anugrah, berdasarkan analisa dan juga pengujian yang dilakukan menggunakan metode Black Box bahwa secara fungsional aplikasi ini sudah menghasilkan hasil output yang diinginkan, sistem yang diterapkan pada aplikasi ini pun telah siap mendukung kebutuhan untuk para pengguna dan juga CV. Dhiyara Anugrah.

Dion Nugroho melakukan penelitian yang berjudulSistem Informasi Penyewaan Alat-Alat Berat Berbasis Web Pada PT. Wirana Jayatama Abadi. Tujuan dari penelitian ini adalah untuk menjadi salah satu teknologi yang dapat mengelola informasi dengan cepat, akurat dan dapat menjangkau semua belahan dunia adalah Internet. Dengan teknologi yang dikenal sebagai internet yaitu sebuah jaringan komputer yang dapat mencakup jaringan skala global artinya jaringan ini dapat mencakup keseluruh dunia sehingga informasi dapat didapatkan tanpa harus pergi ke tempat sumber informasi itu berasal. Berdasarkan situasi tersebut, peneliti tertarik untuk membuat Website dinamis dan interaktif pada PT. Wirana Jayatama Abadi, sebagai media Informasi dengan menghubungkan ke database yang telah dibuat di MySQL. Pembuatan Website ini menggunakan Macromedia Dreamweaver cs 5 adalah sebuah program web editor yang digunakan untuk membuat dan mendesin web. Software ini mempunyai kehandalan dalam membuat dan mendesain web tanpa harus menulis tag-tag html persatu. Maksud dari program ini adalah untuk membuat sebuah program web yang berisi tentang sistem penyewaan alat-alat berat yang membutuhkan strategi dan dapat mengenalkan produknya sehingga masyarakat dapat mengerti alat-alat berat yang telah mereka sewa sebagai salah satu solusi untuk memecahkan masalah meningkatkan penyewaan dan mengenalkan produknya kepada pelanggan tanpa harus mendatangi perusahaan Wirana.

\section{METODE PENELITIAN}

Dalam penelitian ini, peneliti melakukan pendekatan studi kasus dengan metode Research and Development (R\&D) yaitu metode penelitian yang di gunakan untuk menghasilkan produk tertentu, dan menguji ke efektifan produk tersebut. Produk tersebut tidak selalu berbentuk benda atau perangkat keras (Hardware), seperti buku, alat tulis, dan alat pembelajaran lainnya. Akan tetapi, dapat pula dalam bentuk perangkat lunak (Software). Dalam pelaksanaan R\&D, ada beberapa metode yang di gunakan yaitu metode kualitatif dengan pendekatan deskriptif. Penelitian deskriptif merupakan penelitian untuk mengumpulkan informasi mengenai status gelaja yang ada, yaitu keadaan apa adanya pada saat penelitian di lakukan. Melalui metode tersebut bertujuan untuk agar pengumpulan data yang di lakukan memperoleh data yang akurat.

Dalam penelitian ini, peneliti melakukan metode pengumpulan data untuk mendapatkan suatu data yang cukup dengan cara pengumpulan bahan-bahan keterangan dan data yang berhubungan dengan judul penelitian ini, sehingga tidak menyimpang dari pokok permasalahan. Adapun metode yang digunakan adalah:

a. Observasi

Yaitu metode untuk mendapatkan data dengan melakukan pengamatan langsung, pencatatan, dan pengumpulan data-data terhadap proses kerja sistem yang berjalan pada Fisheries Diving Club (FDC) Universitas Hasanuddin.

b. Wawancara

Yaitu melakukan pengumpulan data dengan melakukan tanya jawab dan tinjauan kepada pegawai yang bertugas pada Fisheries Diving Club (FDC) Universitas Hasanuddin. mengenai hal yang berhubungan dengan penelitian ini.

c. Studi Pustaka

Yaitu metode pengumpulan data dengan cara mempelajari beberapa buku, sarana perpustakaan, yang berhubungan dengan penelitian ini. 
Metode pengembangan sistem yang digunakan adalah metode Waterfall, dengan tahapan sebagai berikut :

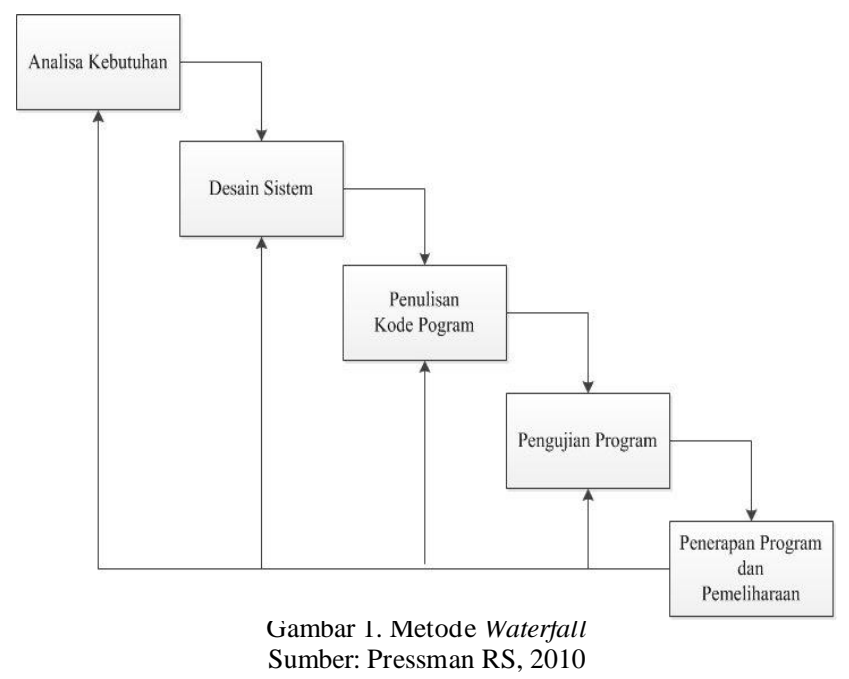

Berikut ini merupakan penjelasan dari langkah-langkah pengembangan sistem dengan metode waterfall:

1. Analisa Kebutuhan

Analisa ini dibutuhkan untuk mengetahui apa saja yang dibutuhkan, bagaimana arus diagram aliran data dalam pembuatan sistem dan perancangan sistemnya, meliputi analisa aturan bisnis sistem, analisa masukan, diagram konteks, kamus data, normalisasi yang dilakukan, format masukan dan format keluaran.

2. Desain Sistem

Tahapan dimana dilakukan penuangan pikiran dan perancangan sistem terhadap solusi dari permasalahan yang ada dengan menggunakan perangkat permodelan ssistem seperti diagram alir data (DAD), diagram hubungan entitas (entity relationship diagram) serta struktur dan bahkan data.

3. Penulisan Kode Program

Penulisan kode program atau coding merupakan penerjemahan design dalam bahasa yang bisa dikenali oleh komputer. Dilakukan oleh programmer yang akan menterjemahkan transaksi yang diminta oleh user. Tahapan ini lah yang merupakan tahapan secara nyata dalam mengerjakan suatu sistem. Dalam artian penggunaan komputer akan dimaksimalkan dalam tahapan ini. Setelah pengkodean selesai maka akan dilakukan testing terhadap sistem yang telah dibuat tadi. Tujuan testing adalah menemukan kesalahan-kesalahan terhadap sistem tersebut dan kemudian bisa diperbaiki.

4. Pengujian Program

Pengujian adalah proses untuk memastikan apakah semua fungsi sistem bekerja dengan baik dan mencari apakah masih ada kesalahan pada sistem. Pengujian sangat penting dilakukan untuk menjamin kualitas software.

5. Penerapan Program dan Pemeliharaan

Perangkat lunak yang sudah disampaikan kepada pelanggan pasti akan mengalami perubahan. Perubahan tersebut bisa karena mengalami kesalahan karena perangkat lunak harus menyesuaikan dengan lingkungan (periperal atau sistem operasi baru) atau karena pelanggan membutuhkan perkembangan fungsional. 


\section{HASIL DAN PEMBAHASAN}

Fisheries Diving Club (FDC) Universitas Hasanuddin Makassar memiliki aturan-aturan bisnis, di antaranya adalah:

1. Admin melakukan penginputan data anggota, data kategori, dan data barang alat-alat selam dan snorkeling yang akan disewa dalam sebuah file database. Admin juga harus memastikan sisa jumlah stok barang alat alat-alat selam dan snorkeling agar tersedia untuk disewa. Jika anggota ingin melakukan penyewaan maka harus login terlebih dahulu. Lain jika yang ingin melakukan penyewaan adalah umum, maka tidak perlu untuk melakukan login. Anggota dan umum mengisi form pemesanan yang telah di sediakan, bila stok masih tersedia anggota dan umum melanjutkan proses mengisi form detail pemesanan barang yang akan di sewa. Admin memberikan barang alat-alat selam dan snorkeling tersebut ke anggota dan umum dan kemudian menginput data penyewaan di file database

2. Admin akan melihat data pemesanan barang yang akan di sewa oleh anggota dan umum dan admin akan melakukan pembalasan konfirmasi untuk dilihat oleh anggota dan umum. Anggota dan umum membawa barang alat-alat selam dan snorkeling untuk diserahkan kepada admin, admin mengecek barang alat-alat selam dan snorkeling, bila ada kerusakan, maka diperhitungkan penggantiannya dan dibebankan kepada anggota. Bila anggota terlambat dalam pengembalian, maka jumlah biaya keterlambatan akan dibebankan kepada anggota dan umum. Admin menginput semua data pengembalian yang ada, setiap pengembalian akan didata dan data-data tersbut disimpan pada file database.

3. Pada setiap akhir bulan admin akan membuatkan laporan data barang, data anggota, data kategori, data penyewaan, dan data pengembalian barang alat-alat selam dan snorkeling untuk diserahkan oleh koordinator Fisheries Diving Club (FDC) Universitas Hasanuddin.

Berikut ini adalah Diagram Alir Data (DAD) yang Diusulkan:

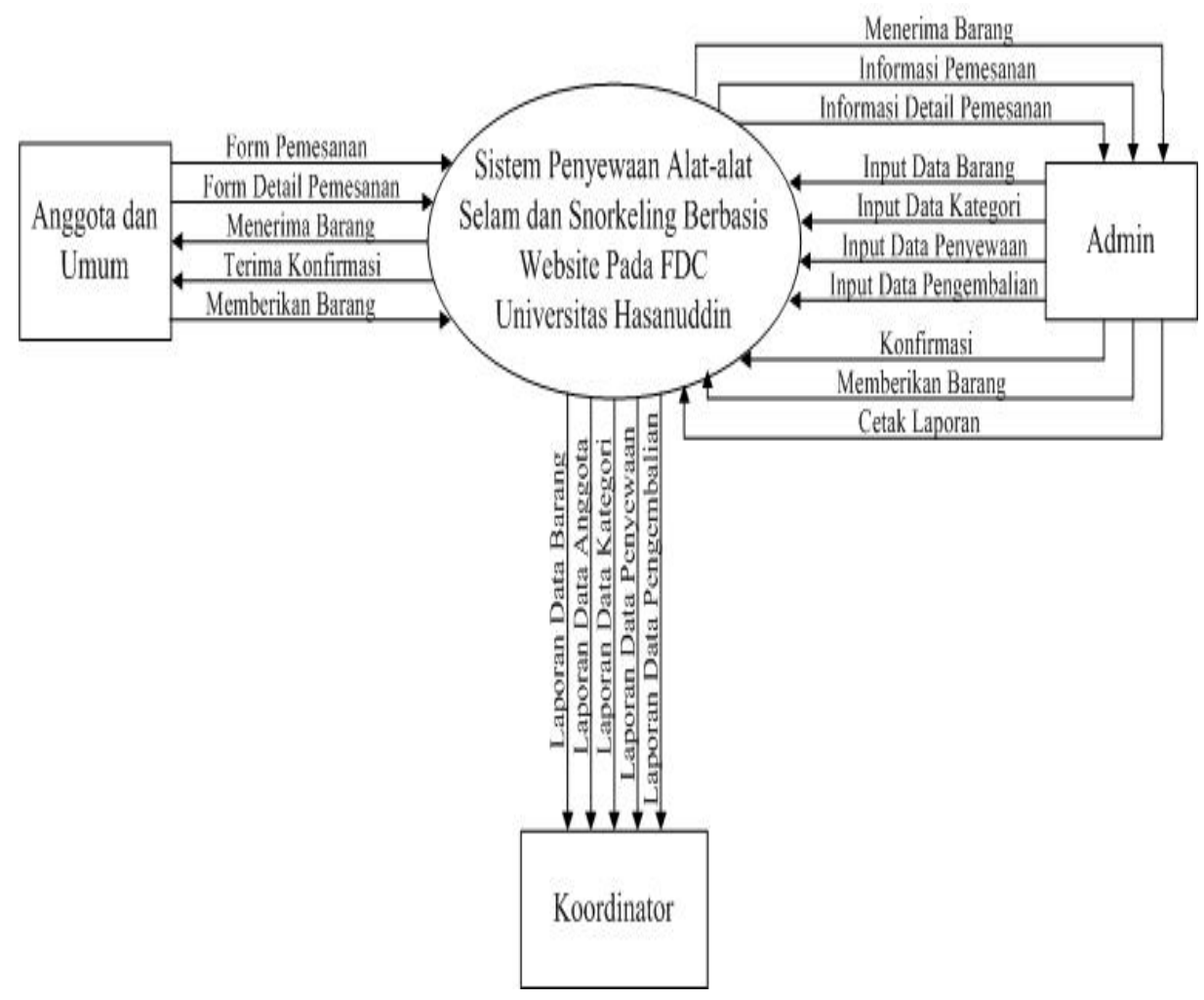

Gambar 2. Diagram Konteks 
Berikut ini adalah Entity Relationship Diagram (ERD):

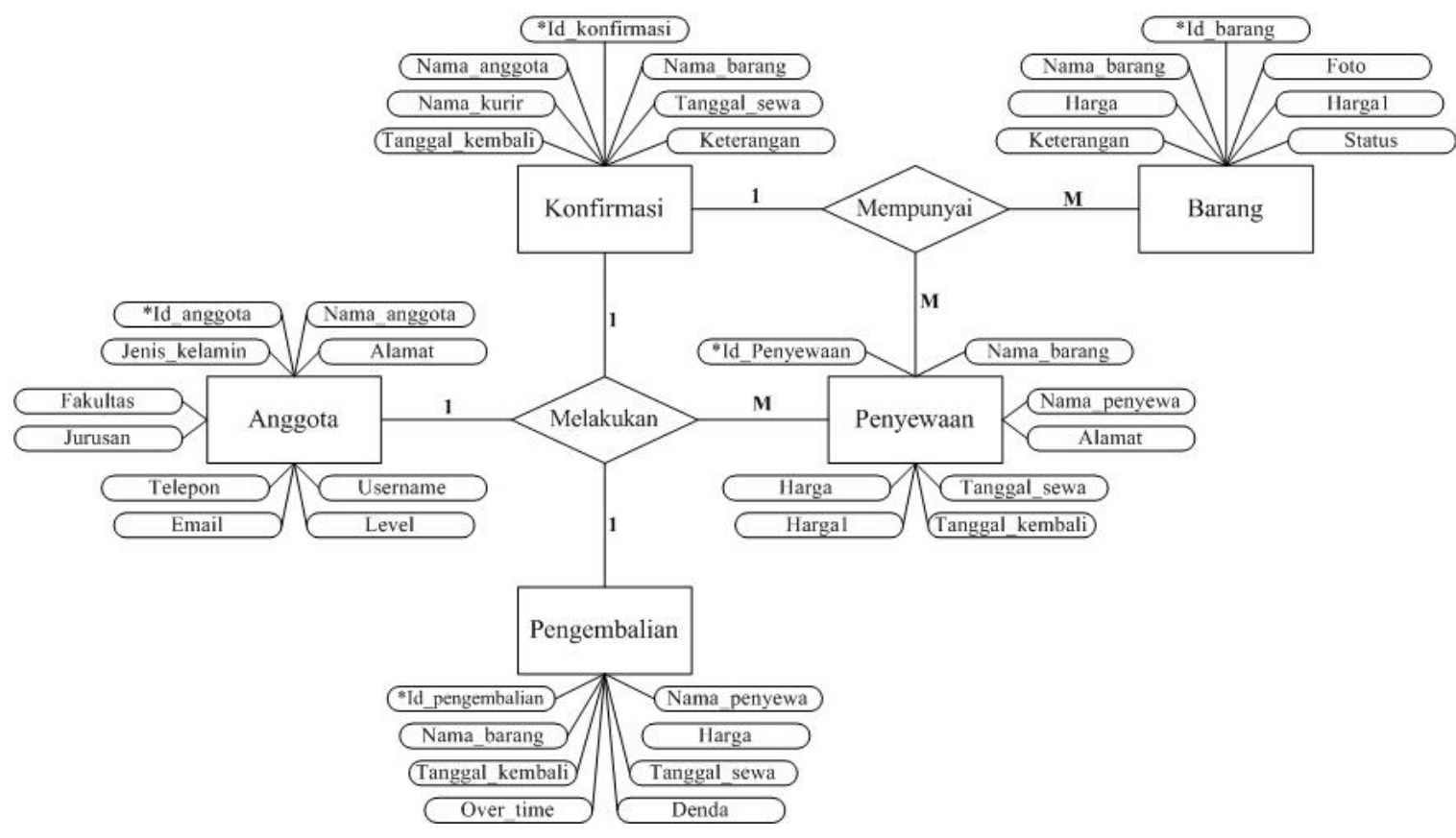

Gambar 4. Entity Relationship Diagram

\section{Tampilan Aplikasi}

Tampilan Menu Login

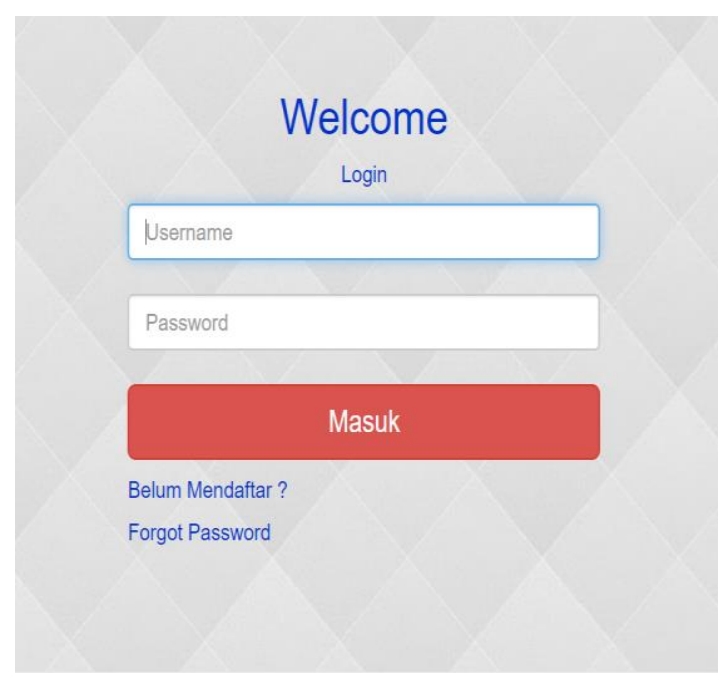

Gambar 5. Mепи Login

Setiap Administrator dan anggota atau orang yang akan menyewa alat-alat selam harus login terlebih dahulu melalui menu ini. 


\section{Tampilan Menu Utama Anggota}

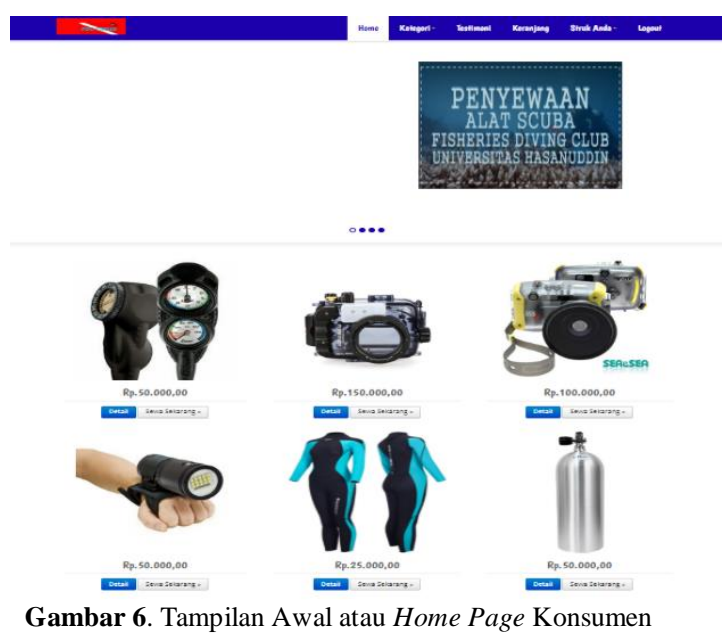

Tampilan ini adalah halaman pertama/ home page yang akan muncul ketika Anggota/penyewa melakukan login.

\section{Tampilan Input Pengambilan Barang / Data Penyewaan}

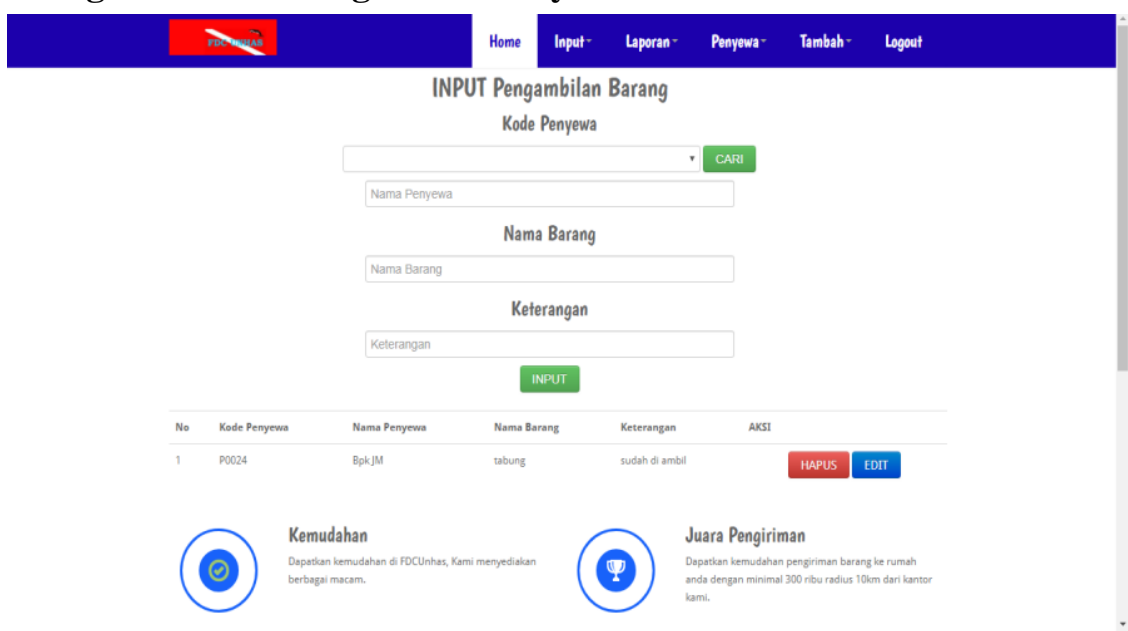

Gambar 6. Tampilan Input Pengambilan Barang/Data Penyewaan

Tampilan ini berisi detail data penyewaan yang sudah di Input, terdiri dari form Input data penyewaan dan form tampilan data penyewaan.

Tampilan Laporan Data Anggota

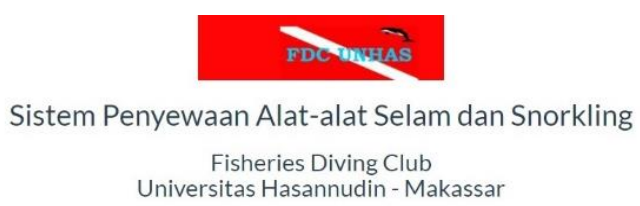

DATA SELURUH ANGGOTA

\begin{tabular}{|lcccccc|}
\hline No. & Nama Lengkap & UserName & Email & No.Telpon & Jenis Kelamin & Alamat \\
\hline 1 & agus & agus & agus@gmail.com & 12345678 & laki-laki & depok \\
\hline 2 & Dedi & dedi & dedi@gmail.com & 815000012 & lakk-laki & Bogor \\
3 & Eli & eli & eliemail.com & 856000012 & perempuan & Bekasi \\
\hline 4 & erlangga & erlangga & erlangga@gmail.com & 123455663 & laki-laki & curug \\
\hline 5 & rudi & rudi & rudi@gmail.com & 987654321 & laki-laki & cijantung \\
\hline
\end{tabular}




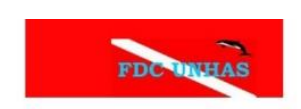

Sistem Penyewaan Alat-alat Selam dan Snorkling

Fisheries Diving Club

Universitas Hasannudin - Makassar

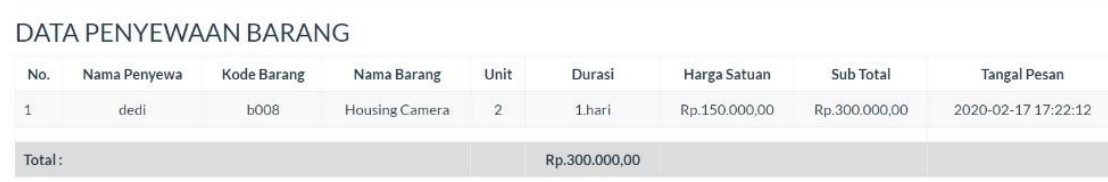

Jakarta, Senin 17 Februari 2020
Kepala Koordinator

Ayyub Khan

Tampilan Laporan Data Penyewaan

Gambar 8. Laporan Data Penyewaan

Tampilan ini merupakan tampilan untuk menampilkan laporan data Penyewaan Barang yang telah dicetak.

\section{SIMPULAN}

Sistem penyewaan barang alat-alat selam yang sedang berjalan saat ini masih dilakukan secara manual, baik itu dalam pencatatan data maupun pembuatan laporan. Dengan adanya sistem informasi penyewaan barang alat-alat selam dan snorkeling berbasis Java ini dapat memudahkan dan membantu dalam proses pengolahan dan penginputan data agar lebih efektif dan efisien. Sistem Informasi penyewaan barang alat-alat selam dan snorkeling yang telah dibuat bertujuan untuk mempermudah pekerjaan yang sebelumnya masih dilakukan secara manual, namun sistem yang dibuat pasti memiliki kekurangan, oleh karena itu perlu adanya evaluasi yang dinilai masih belum baik terhadap sistem yang telah dibuat, misalya dengan cara selalu memperbarui dan melakukan inovasi terhadap sistem informasi tersebut.

\section{DAFTAR PUSTAKA}

Ardhana, YM Kusuma. (2012). Menyelesaikan Website 30 Juta. Jakarta: Jasakom.

Indrajani. (2015). Perancangan Basis Data dalam All in 1. Jakarta: PT. Elex Media Komputindo.

Kimmel, Weygant, Kieso. (2011). Akuntansi Intermediate. Jakarta: Erlangga.

Nugroho. (2013). Mengenal XAMPP Awal. Yogyakarta: MediaKom.

Parno. (2009). Modul Sistem Informasi dan Sistem Analisis. Yogyakarta: Andi Offset.

Raharjo, Budi. (2011). Membuat Database Menggunakan MySql. Bandung: Informatika.

Safaat, H. Nazruddin. (2012). Pemograman Aplikasi Mobile Smartphone dan Tablet PC Berbasis Android. Bandung: Informatika.

Subhan, Mohamad. (2012). Analisa Perancangan Sistem. Jakarta: Lentera Ilmu Cendekia.

Sukamto, R. A., dan Shalahudin, M. (2014). Modul Pembelajaran Rekayasa Perangkat Lunak (Terstruktur Dan Berorientasi Objek). Bandung: Modula Bandung.

Supono, dan V. Putratama. (2016). Pemograman Web Dengan Menggunakan PHP dan Framework Codeigniter. Yogyakarta: Deepublish.

Susanto, Ahmad. (2013). Teori Belajar dan Pembelajaran di Sekolah Dasar. Jakarta: Kencana Prenada Media Group. Sutabri, Tata. (2012). Analisis Sistem Informasi. Yogyakarta: Andi. 